\title{
O CONHECIMENTO HISTÓRICO VULGARIZADO: A "DITADURA" DO MANUAL DIDÁTICO
}

\author{
Carla Villamaina Centeno ${ }^{1}$ \\ Universidade Estadual de Mato Grosso do Sul - UEMS \\ carla.centeno@uol.com.br
}

\section{RESUMO:}

Este artigo tem por objetivo realizar uma crítica acerca do conhecimento histórico transmitido em sala de aula, nos níveis de ensino fundamental e médio. É motivado por várias críticas acerca da utilização indiscriminada do manual didático. Segundo alguns autores, o manual estaria determinando o que deve ser ensinado aos estudantes e vulgarizando o ensino. Num primeiro momento, o texto aborda a gênese do manual didático e, num segundo momento, desenvolve a crítica. $\mathrm{O}$ manual didático impera com poder absoluto nas escolas e vem disfarçado também sob o nome de apostila. $\mathrm{O}$ conhecimento que ele veicula é fragmentado e simplificado por não proporcionar o acesso a fontes e pensamentos diversos e opostos.

Palavras-chave: Conhecimento histórico, ensino de História, manual didático, ensinos fundamental e médio.

\section{THE HISTORICAL KNOWLEDGE POPULARIZED: THE "DICTATORSHIP" OF THE EDUCATIONAL MANUAL}

\begin{abstract}
:
The aim of this article is to criticize the historical knowledge taught in classroom, in the levels of primary and secondary education. It is motivated by several criticism about the indiscriminate utilization of the educational manual that, according to some authors would be determining what may be taught to the students and popularizing the education. In a first moment, the text approaches the genesis of the educational manual and in a second one develops to critical. The educational manual reigns with absolute power in the schools and comes also disguised under the name of class notes. The knowledge that it propagates is fragmented and simplified for not to provide the access to sources and opposite and diverse thoughts.
\end{abstract}

Keywords: Historical knowledge, History teaching, educational manual, primary and secondary education.

\section{Introdução}

Este artigo tem por objetivo realizar uma crítica acerca do conhecimento histórico transmitido em sala de aula, por meio dos manuais didáticos, nos níveis do ensino fundamental e médio.

O manual, segundo pesquisas recentes, seria a única fonte utilizada e estaria determinando, orientando e dando a tônica ao ensino.

A discussão pode ser iniciada com a formulação de uma questão geral: de que forma o conhecimento histórico, tal como é produzido na academia, está sendo veiculado em sala de aula? Ou, dito de outra forma, as especificidades inerentes aos procedimentos 
científicos, tais como a utilização dos instrumentais próprios do fazer científico na área de história, a utilização, a análise e a crítica das fontes estão sendo, de alguma forma, pleiteados na transmissão do conhecimento histórico em sala de aula?

\title{
O conhecimento histórico e o ensino: fundamentos para compreensão da atual organização do trabalho didático
}

O pressuposto inicial é o de que qualquer abordagem acerca do trabalho didático, tal como se realiza em sala de aula, envolvendo os procedimentos pedagógicos do professor, o instrumental utilizado e o conteúdo didático selecionado, impõe um recuo aos primórdios da escola moderna. Esse recuo é necessário porque torna inteligíveis as bases em que a escola contemporânea está assentada e alguns dos problemas postos na área especializada do ensino de História.

A escola de nosso tempo, organizada por níveis de ensino e seriação dos estudos, teve origem no século XVII com Comenius, pastor protestante, nascido na Morávia. É o que afirma Alves (2005, p. 59).

Comenius está na origem da escola moderna. A ele, mais do que a nenhum outro, coube o mérito de concebê-la. Nessa empreitada, foi impregnado pela clareza de que o estabelecimento escolar deveria ser pensado como uma oficina de homens (ALVES, 2006, p. 71).

Comenius formulou numa forma mais desenvolvida a proposta educacional da Reforma Protestante. Por oposição à orientação emanada da Igreja Católica, a Reforma postulava a todos os seres humanos, inclusive aos trabalhadores camponeses, o livre acesso às Escrituras Sagradas. Para tanto, fazia-se necessário o domínio elementar da escrita e da leitura, algo, até então, reservado a uma parte da classe dominante ${ }^{2}$. Em sua obra mais significativa, Comenius se propõe a fundar as bases da escola moderna, por meio da

\begin{abstract}
Didáctica Magna: tratado da arte universal de ensinar tudo a todos ou processo seguro e excelente de instituir, em todas as comunidades de qualquer reino cristão, cidades e aldeias, escolas tais que toda a juventude de um e de outro sexo, sem exceptuar ninguém em parte alguma, possa ser formada nos estudos, educada nos bons costumes, impregnada de piedade, e, desta maneira, possa ser, nos anos de puberdade, instruída em tudo o que diz respeito à vida presente e à futura, com economia de tempo e de fadiga, com agrado e com solidez (COMENIUS, 1976, p. 43)
\end{abstract}

À época, o conhecimento era predominantemente veiculado pela ação de mestres ou preceptores, detentores de vastos conhecimentos, sábios por excelência. O preceptor era dotado de sólida formação humanística e seu trabalho era complexo por que exigia o domínio amplo do conhecimento e, por essa razão, seus estipêndios eram elevados $\mathrm{O}$ ensino era ministrado individualmente ou em pequenos grupos e não estava regido por um plano de estudos, divisão por séries ou por graus de adiantamento. Os conteúdos didáticos, na forma de extratos, eram retirados dos clássicos e as vertentes das fontes variavam conforme as diferentes conjunturas históricas. Não havia, à época, ambientes reservados para o ensino como prédios escolares. Os espaços em que se realizava o trabalho educativo eram públicos, abertos, a exemplos das praças e jardins, ou privados, em ambientes reservados da casa do discípulo ou do preceptor.

Nessa forma de organização artesanal do trabalho didático era impossível, na visão de Comenius, difundir a escola para todos. Os custos do preceptor eram elevados, os livros 
também eram raros e caros e não havia edificações escolares especializadas para o ensino. De onde viriam os recursos para pagar os mestres, por exemplo? Motivado pela necessidade social de levar as primeiras letras a todos os seres humanos, Comenius concebeu uma instituição social especializada, a escola moderna, cuja finalidade era "ensinar tudo a todos". Esta instituição deveria inserir a divisão do trabalho no trabalho didático tal como já acontecia nas manufaturas. Para ele, o estabelecimento escolar deveria ser pensado como uma oficina de homens, ou seja, como uma manufatura.

[...] Na verdade, há uma grande economia de fadiga e de tempo, quando uma só pessoa faz uma só coisa, sem ser distraída por outras coisas; deste modo, com efeito, uma só pessoa pode servir ùtilmente a muitas, e muitas podem servir a uma só [...]

A arte de ensinar nada mais exige, portanto, que uma habilidosa repartição do tempo, das matérias e do método. Se a conseguirmos estabelecer com exactidão, não será mais difícil ensinar tudo à juventude escolar, por mais numerosa que ela seja, que imprimir, com letra elegantíssima, em máquinas tipográficas, mil folhas por dia, ou remover, com a máquina de Arquimedes, casas, torres ou qualquer outra espécie de pesos, ou atravessar num navio o oceano e atingir o novo mundo. (COMENIUS, 1976, p.136, 185 - 186 )

A manufatura apropriou-se da base técnica do artesanato, mas representava sua superação, pois por meio da divisão do trabalho decompôs o ofício do trabalho medieval. Especializou os trabalhadores, os instrumentos de trabalho e eliminou o domínio do trabalhador no processo de trabalho como um todo. De fato, Comenius viajara por toda a Europa e teve acesso a discussão sobre a ciência moderna e aos avanços na produção de mercadorias decorrente da instauração da divisão do trabalho.

Tomando por base o trabalho produtivo, para ele, era possível e necessário implantar a divisão do trabalho na escola, tal como se dera na manufatura, gerando mais resultados, com economia de tempo, de fadiga e de recursos. Para ele a escola deveria ser o local

Onde os fundamentos de todas as coisas que se aconselham são tirados da própria natureza das coisas; a sua verdade é demonstrada com exemplos paralelos das artes mecânicas; o curso dos estudos é distribuído por anos, meses, dias e horas; e, enfim, é indicado um caminho fácil e seguro de pôr estas coisas em prática com bom resultado.

A proa e a popa da nossa Didáctica será investigar e descobrir o método segundo o qual os professores ensinem menos e os estudantes aprendam mais; nas escolas, haja menos barulho, menos enfado, menos trabalho inútil, e, ao contrário, haja mais recolhimento, mais atractivo e mais sólido progresso; na cristandade, haja menos trevas, menos confusão, menos dissídios, e mais luz, mais ordem, mais paz e mais tranqüilidade. (COMENIUS, 1976, p.136)

Para Alves (2005, p. 75) a preocupação de Comenius com os determinantes materiais tem passado despercebida aos historiadores que analisam sua obra. Comenius tinha consciência, segundo o autor, das dificuldades econômicas para implantar a escola para todos. A proposta comeniana visava ao barateamento da escola, pois a queda de custos era condição primordial à sua universalização (ALVES, 2005, p. 74-75). Mas à sua 
época existiam impedimentos desde a falta de educadores conhecedores do método, bem como de instrumental de trabalho para orientar o trabalho didático nos novos moldes.

O remédio para essa dificuldade, segundo o pastor protestante, deveria ser buscado, prioritariamente, na transformação do instrumental do trabalho didático. Para Comenius, somente com a produção e inserção de instrumentos que orientassem e expusessem todos os conteúdos era possível viabilizar a escola para todos. Denominados por ele de "livros pan-methódicos" esses seriam os instrumentos mais importantes da máquina escolar.

Uma só coisa é de extraordinária importância, pois, se ela falta, pode tornar-se inútil toda a máquina, ou se está presente, pode pô-la toda em movimento: uma provisão suficiente de livros pan-metódicos. (COMENIUS, 1976, p. 469)

Segundo Alves (2005, p. 76):

Surgia um novo instrumento de trabalho do professor: o manual didático. Quanto à sua forma e à sua função, essa nova tecnologia educacional distinguia-se tanto dos livros clássicos, até então muito caros e pouco universalizados como decorrência dos limites próprios da produção manufatureira, e das antologias, subprodutos escolares dos livros clássicos, pois nestes selecionavam os extratos que as compunham. (ALVES, 2005, p. 76)

O manual possibilitaria a queda de custos, pois realizava certo grau de simplificação e de objetivação do trabalho didático. Com a revolução no instrumental, expressa no surgimento do manual didático, qualquer homem de capacidade intelectual mediana poderia ensinar. Para que a escola se universalizasse era necessário, então, transformar o educador em trabalhador especializado, retirar-lhe em grande parte o domínio teórico-prático do trabalho que realizava. O próprio Comenius apontou que esse novo profissional, o professor, dado o seu grau de especialização, não poderia formular os conteúdos expostos nos manuais. Para isso, deveria ser contratado um novo tipo de trabalhador especializado: o compendiador. Este passava a selecionar e resumir os conteúdos, que, materializados nos manuais didáticos, passavam a nortear o trabalho em sala de aula. O manual didático, além de resumir um programa de conteúdos informativos, os dispunha em ordem seqüencial e condicionava os procedimentos docentes necessários ao seu uso. Enfim, dava a tônica ao trabalho didático.

Contudo, essa tecnologia, o manual, não se expandiu plenamente em sua época. Ela somente ganhou maior difusão no final do século XIX e, sobretudo, no século XX, por força não só do grande desenvolvimento tecnológico que barateou os livros, mas, sobretudo, do aumento da demanda por educação.

\section{A produção dos manuais a partir do século XIX no Brasil}

No caso do Brasil, os manuais de História se tornaram referência a partir de meados do século XIX, mas limitados ainda aos colégios secundários. Os primeiros manuais de História Universal, segundo Guy de Hollanda (1957: 104), eram importados da França. Foi o caso, por exemplo, de Histoire de La Civilization, manual de Ch. Seignobos, adotado nas escolas secundárias que seguiam o modelo dos programas do Colégio Pedro II (Hollanda, 1957: 104). Os manuais brasileiros foram produzidos, em sua maior parte, pelos professores do Colégio Pedro II, a exemplo dos de Joaquim Manoel de Macedo, 
Capistrano de Abreu. Esses professores eram não somente os responsáveis pela fixação dos programas, mas, frequientemente, participavam, também, do Instituto Histórico e Geográfico do Brasil, daí comungarem, este e o Colégio Pedro II, "o mesmo arcabouço conceitual e problematização" do conhecimento histórico (ABUD, 1998, p. 30).

$\mathrm{Na}$ área de história foi muito difundido, desde o final do século XIX, o manual Lições de História do Brasil, de Joaquim Manuel de Macedo, "obra adoptada pelo Conselho Superior da Instrucção publica para uso das escolas de ensino primário" (MACEDO, 1905, folha de rosto). Esse manual desenvolvia a lição e trazia também as explicações a ela referentes, para orientar o professor. Em seguida, vinham o quadro sinótico e as perguntas para resumir e orientar a memorização do conteúdo pelo aluno (MACEDO, 1905, p. 1).

A partir da década de 1930 os manuais escritos em língua estrangeira foram proibidos. Entre os compêndios mais utilizados, até a década de 1940, destacavam-se Epítome de História Universal, de Jonathas Serrano, e História Universal, de João Ribeiro (HOLLANDA, 1957, p. 108-10).

Mas, esses manuais, ainda na época referida, não eram predominantes no ensino. Foram incorporados ao trabalho didático como instrumentos auxiliares de professores.

Hoje, o manual domina o processo de ensino. E, como Comenius previra, surge o manual que define o ensino e se torna determinante: "[...] acima de tudo, desejo e solicito que os assuntos sejam expostos em linguagem familiar e comum, para permitir que os alunos entendam tudo espontaneamente, mesmo sem mestre (COMENIUS, 1976, p. 217, grifos nossos) [...]".

Pesquisadores que tratam o manual didático como objeto de investigação, entre eles Munakata (1998), Bittencourt (1998), Fonseca (2003), Alves (2005), Deiró (1981), Bonazzi \& Eco (1980) e Gatti Junior (2004), admitem ser ele o instrumento que orienta, veicula o conhecimento, organiza e informa todo o processo de ensino. Ele é o instrumento que impõe um certo grau de objetivação ao trabalho didático e, na mesma medida, estabelece o domínio sobre as operações realizadas pelo professor em sala de aula, daí, segundo Fonseca, ser a fonte definidora do ensino.

Pesquisas publicadas nos últimos anos têm analisado os conteúdos veiculados pelo livro didático de História, os significados de sua ampla utilização no Brasil e as formas alternativas ao uso deste material, que muitas vezes tem se tornado o definidor do processo de ensino (FONSECA, 2003, p. 141, grifos nossos).

O instrumental próprio do fazer científico e o próprio conteúdo da produção científica na área de história não penetram o espaço escolar. A forma de se fazer pesquisa nas diversas áreas do conhecimento, os procedimentos específicos e as técnicas próprias de cada uma delas, não são incorporados ao trabalho didático. $\mathrm{E}$ a pesquisa não tem lugar na escola porque o manual a exclui, já que, por princípio, deve conter todo o conhecimento a ser transmitido, não importa se simplificado, se parcial, se falso e se distorcido pela ideologia. A própria imprensa, sistematicamente, faz reportagens dando conta do caráter vulgar e problemático do conhecimento veiculado pelos manuais didáticos.

Se, de fato, a prática de utilização do manual didático foi uma necessidade posta pela época de Comenius, pois ainda eram limitados os recursos para efetivar a educação para todos, hoje nada a justifica. A organização manufatureira do trabalho didático, associada à utilização do manual, representou uma ruptura com o conhecimento culturalmente significativo e impôs o império desse instrumento de trabalho. $\mathrm{O}$ conhecimento foi vulgarizado, na escola, por força de sua veiculação pelo manual didático. 
[...] O livro didático é limitado e condicionado por razões econômicas, ideológicas e técnicas. A linguagem que produz deve ser acessível ao público infantil e juvenil e isso tem conduzido a simplificações que limitam sua ação na formação intelectual mais autônoma dos alunos. Autores e editores ao simplificarem questões complexas impedem que os textos dos livros provoquem reflexões ou possíveis discordâncias por parte dos leitores. Sua tendência é de ser um objeto padronizado, com pouco espaço para textos originais, condicionando formatos e linguagens, com interferências múltiplas em seu processo de elaboração associadas à lógica da mercantilização ${ }^{3}$ e das formas de consumo. (BITTENCOURT, 1998, p. 73)

O fenômeno denominado por Alves de império do manual didático (ALVES, 2005, p. 231) impede que os estudantes tenham acesso à produção científica e às demais fontes do conhecimento, à riqueza cultural da humanidade enfim. Por meio do manual didático, o que se veicula dentro da escola é o conhecimento vulgarizado, simplificado e fragmentado, que exclui o acesso a todas as demais fontes do conhecimento culturalmente significativo.

O aviltamento dos conteúdos didáticos poderia ser entendido como resultado singular, restrito nos seus efeitos aos trabalhadores. Não é o caso. Analisando-se o processo de expansão da escola pública, o que se verifica é o domínio desse traço, que progressivamente assumiu o caráter de tendência geral. Os manuais didáticos, consumidos indistintamente pelos filhos dos trabalhadores, das camadas médias e mesmo da burguesia, desde então, podem ser tomados como os indicadores que incorporam e revelam essa tendência dominante. É expressiva, por exemplo, a forma pela qual os manuais didáticos difundem a imagem da sociedade e das coisas humanas. É uma imagem não contraditória, à qual se acopla, harmoniosamente, a própria "imagem pequeno burguesa" da escola (ALVES, 2005, p. 168)

Ainda segundo Alves (2005, p. 170-173), somente os filhos da alta burguesia dispõem de meios para fugir dos efeitos dessa tendência.

Só têm escapado aos efeitos dessa tendência os filhos de uma burguesia e de executivos privilegiados que valorizam o refinamento cultural. Para essas crianças, o acesso à educação não se vê cerceado pelo elevado custo dos serviços propiciados por um selecionadíssimo grupo de escolas particulares. Mesmo assim, caberia investigar até que ponto o resultado pleiteado se viabiliza na prática [...] Intencionalmente, essas escolas vêm reduzindo o número de alunos por sala de aula, medida que tem diminuído acentuadamente a relação professor-aluno. Não se trata de diminuição da demanda, pois elas realizam concorridas seleções de sua clientela tanto na entrada do ensino fundamental como na do ensino médio. Seus professores também são rigorosamente selecionados e, pelos dados apresentados, já não se cogita de recrutar exclusivamente artistas cujo gestual e facilidade de expressão cativam a atenção dos alunos mas, sim, quadros que dispõem de sólida formação humanístico-científica. Sob esse aspecto, é muito expressivo o depoimento do dirigente de um desses colégios que, entre outras atribuições, realiza a seleção de professores. "Costumo perguntar os livros que os candidatos lêem e que já leram", diz ele. "Se citam Machado de Assis, conversamos. Se falam em Paulo 
Coelho, encerro a entrevista." Os salários pagos ao magistério superam em muito aos dos professores das escolas públicas dos estados mais ricos do País, chegando a equiparar-se aos dos professores com mestrado e doutorado das universidades federais e estaduais contratados em regime de dedicação exclusiva (ALVES, 2005, p. 170-173)

Quando se discute a questão do aviltamento do conteúdo didático nas escolas em geral, a análise não tem em vista os resultados de pesquisas comuns nas décadas de 1970 e 1980, que davam conta da função de reprodução ideológica dos manuais didáticos e, como decorrência, da própria escola ${ }^{4}$. Essa função sempre esteve presente no funcionamento das instituições escolares e, portanto, sempre foi óbvia. Mais significativas foram as pesquisas que mostraram, por dentro, os mecanismos pelos quais os manuais distorcem o conhecimento para atender interesses hegemônicos das classes dirigentes. Uma investigação exemplar, na área de história, foi a realizada por Cerqueira Filho \& Neder (1978). Analisando manuais escolares aprovados pelo programa nacional do livro didático, constataram que a violência nas relações sociais, desde a época da colonização, é sistematicamente ocultada. Em seu lugar, sobrepõe-se a valorização da conciliação ${ }^{5}$. Eis recolocada a questão da vulgarização do conhecimento que circula no âmbito das escolas.

Muitos educadores entendem que a questão se reduz a uma reforma dos manuais didáticos. De fato, não é possível aperfeiçoar o manual, pois o problema não está somente na ideologia e sim na função exercida por esse instrumento no trabalho didático. Ele se impõe como fonte única do conhecimento e exclui todas as demais. Exclui, portanto, o conhecimento culturalmente significativo, veiculado pelos livros clássicos e por sites das grandes bibliotecas e museus dos diversos continentes. A inserção de variadas fontes, novas tecnologias e de novas linguagens no trabalho didático tem ficado no plano do discurso.

Uma prova cabal da "força dos manuais" é a atual adoção de apostilas pela Secretaria de Educação do Estado de São Paulo com o objetivo de padronização das aulas.

Em artigo intitulado "São Paulo começa a usar apostila única para orientar professores", publicado no Jornal O Estado de São Paulo, em 18.02.2008, Cafardo afirma:

As escolas estaduais de São Paulo começam hoje, volta às aulas, a usar um material didático em forma de apostila para orientar professores sobre como proceder e quais conteúdos abordar em sala de aula. Essa é a primeira vez que a rede, com 200 mil professores e 5 mil escolas, tem um material único de proposta curricular para $5^{\mathrm{a}}$ a $8^{\mathrm{a}}$ séries e ensino médio. Os livros elaborados pelo governo funcionam como guias - detalham o que deve ser feito aula a aula, indicam as habilidades dos alunos que precisam ser trabalhadas e propõem avaliações. Mas há quem reclame que o formato massifica a maneira de ensinar (CAFARDO, 2008, grifos nossos).

Segundo a mesma matéria, o Sindicato dos Professores do Ensino Oficial do Estado de São Paulo - APEOESP - não teria aprovado a solução:

'Esse material tira o direito do professor de conduzir sua aula', diz o presidente do sindicato dos professores (Apeoesp), Carlos Ramiro, que teve acesso aos livros. Para ele, a proposta curricular é apresentada como 'apostilas usadas em sistemas de ensino particular', numa forma de padronização do ensino. (CAFARDO, 2008) 
$\mathrm{Na}$ verdade, o dirigente sindical não percebeu que o professor já não conduz a sua aula, por força da determinação dos manuais. O dirigente sindical também não percebeu que os manuais do programa nacional do livro didático e as apostilas do governo de São Paulo são a mesma coisa, pois têm as mesmas características e exercem a mesma função no trabalho didático. Introduzidos na atividade de ensino, excluem qualquer alternativa de trabalho criativo e exploração de recursos e instrumentos mais avançados.

Para a superação desse quadro é necessária uma ampla discussão dos problemas do ensino envolvendo, em especial, os responsáveis pelo trabalho em sala de aula. Mas, como fazer isto se esses profissionais, os professores, também são especializados na tarefa parcial de transmitir os conteúdos dos manuais? Nos cursos de formação de professores, nas licenciaturas, também o conhecimento tem sido veiculado por meio de manuais, o que não só exclui o acesso ao conhecimento culturalmente significativo, mas reforça e perpetua o círculo vicioso que determina esse tipo de exclusão.

Os profissionais da educação precisam ter acesso ao patrimônio cultural da humanidade, ao saber erudito, aos resultados da pesquisa científica, para recuperar o controle do trabalho didático. Só assim terão o domínio do que deve ser transmitido em sala de aula.

Numa crítica dirigida ao Plano de Desenvolvimento da Educação - PDE, lançado pelo governo federal em 2007, José de Souza Martins elogia o fato de o referido plano ter se preocupado com a melhoria das condições materiais das escolas e com a adoção de exames de avaliação do rendimento escolar. Contudo, para Martins, foram omitidos dois fatores por ele considerados revolucionários na educação. O primeiro seria o compromisso com a implantação da escola integral, previsto pela Lei de Diretrizes e Bases da Educação. O outro seria a difusão da

[...] cultura, no seu amplo e fundamental sentido. Uma revolução na educação pressupõe o currículo revolucionado pelos mecanismos de acesso à grande cultura, já na escola elementar: o teatro, a música, a literatura, a ciência, a pintura, a escultura, a fotografia e, sobretudo, a poesia. Porque sem poesia, a escola fenece e a educação sucumbe (MARTINS, 2007).

Finalizando, reafirme-se que a ampla utilização de manuais didáticos nas diversas áreas do conhecimento integrantes dos currículos escolares exclui o fazer científico típico de cada uma delas, bem como os instrumentos necessários para tal. Logo, também no ensino de História estão excluídos o seu fazer científico típico e os instrumentos que aciona para produzir o conhecimento, como a pesquisa com variadas fontes, por exemplo. É preciso pleitear a possibilidade de, mesmo em face dos limites postos pela organização manufatureira do trabalho didático na atualidade, ser possível incorporar o conhecimento científico e a forma de fazer pesquisa em História, dentro da escola, com o uso de seus procedimentos e técnicas apropriados. Para tanto, urgem a superação do manual didático e a incorporação de novos instrumentos de trabalho, pontes que nos remetem à instauração da relação educativa que se faz necessária em nosso tempo. 


\section{Referências Bibliográficas}

ABUD, Kátia. Currículos de História e políticas públicas: os programas de História do Brasil na escola secundária. In: BITTENCOURT, Circe (Org) O saber histórico na sala de aula. 2. ed. São Paulo:Contexto, 1998.

ALVES, Gilberto Luiz. O trabalho didático na escola moderna: Formas Históricas. Campinas, SP: Autores Associados, 2005

ARRUDA, Élcia Esnarriaga de; SILVEIRA, Giovani. Silveira da. O impacto da expansão escolar no mercado de material didático-pedagógico. In: Seminário Nacional de Estudos e Pesquisas "História, Sociedade e Educação no Brasil", 6, 2003, Campinas, OS. Anais...Campinas/SP: UNICAMP.

BITTENCOURT, Circe. Livros didáticos entre textos e imagens. In: .(Org.). $O$ saber histórico na sala de aula. 2. ed. São Paulo:Contexto, 1998

BONAZZI, Marisa e ECO,Umberto. Mentiras que parecem verdade. Trad. de Giacomina Faldini. São Paulo: Summus. (Novas buscas em educação, 6), 1980

CAFARDO, Renata. "São Paulo começa a usar apostila única para orientar professores". $O$ Estado de São Paulo. 18, fev. 2008. São Paulo, SP. Acesso em: 18 fev. 2008 In: http://txt.estado.com.br/editorias/2008/02/18/ger-1.93.7.20080218.11.1.xml, 2008.

CERQUEIRA FILHO, Gisálio e NEDER, Gizlene. "Conciliação e violência na história do Brasil”. Rio de Janeiro, Encontros com a Civilização Brasileira, n.2, 1978

COMÉNIO, João Amós. Didáctica Magna: tratado da arte universal de ensinar tudo a todos. $2^{\circ}$ ed. Lisboa: Gulbenkian, 1976.

DEIRÓ, Maria de Lourdes Chagas. As belas mentiras: a ideologia subjacente aos textos didáticos. 10.ed. São Paulo: Moraes, 1981.

FARIA, Ana Lúcia G. de. Ideologia no livro didático. 2. ed. São Paulo: Cortez; Autores Associados. (Coleção Polêmicas do Nosso Tempo, 7), 1984.

FONSECA, Selva Guimarães. Caminhos da História Ensinada. 7. ed. Campinas: Papirus, 2003.

GATTI JUNIOR, Décio. A escrita escolar da História: livro didático e ensino no Brasil (1970-1990). Bauru, SP: Edusc; Uberlândia,MG: Edufu, 2004

HOLLANDA, Guy de. Programas e compêndios de história para o ensino secundário brasileiro: 1931-1956. Rio de Janeiro: INEP/Centro Brasileiro de Pesquisas Educacionais.. (Currículos, programas e métodos, 1), 1957.

MACEDO, Joaquim Manoel de. Lições de História do Brasil. Rio de Janeiro: Garnier, 1905. 
MARTINS, José de Souza. "Plano para educar a educação?" O Estado de São Paulo. São Paulo,SP, p. J5 - J5, 29 abr. 2007.

MUNAKATA, K. "História que os livros didáticos contam, depois que acabou a ditadura no Brasil". IN: FREITAS, Marcos Cezar (org) Historiografia brasileira em perspectiva. São Paulo/Bragança Paulista: Contexto/USF. 1998.

\footnotetext{
${ }^{1}$ Licenciada em História e Doutora em História e Filosofia da Educação/UNICAMP. Professora de História e Filosofia da Educação da Universidade Estadual de Mato Grosso do Sul -UEMS- Curso de Geografia, Jardim/MS. Membro do HISTEDBR /MS

${ }^{2}$ Um século antes, para fazer frente ao poder da Igreja Católica, vamos encontrar em Lutero a defesa de que o Estado assumisse para si a tarefa de controlar a instrução, argumentando sobre a necessidade de as escolas ficarem sob o controle estatal. Evidentemente, a ação de Lutero era expressão dos movimentos de transição econômica que já sacudiam toda a Europa.

${ }^{3}$ Autores como Alves (2005: 192), Bittencourt (1998: 73), Fonseca (2003: 139); Arruda \& Silveira (2003: 66) e Munakata (1998: 274), dentre outros, discutem o mercado do livro didático. Esta não é questão central no presente artigo, mas, afirme-se, é muito importante. Enquanto mercadoria, o livro didático domina mais da metade do mercado editorial no Brasil e, por força do programa nacional do livro didático, torna o Estado um comprador monopólico.

${ }^{4}$ Bonazzi \& Eco (1980); Deiró (1981); Faria (1984).

${ }^{5}$ Há (...) tendência nítida na literatura didática do $1^{\circ}$. Grau, especialmente nas disciplinas de Moral e Civismo e Organização Social e Política Brasileira, em se veicular uma imagem do brasileiro típico, como 'religioso, pacífico, cordial, individualista, cônscio dos seus deveres cívicos'. Tal imagem de brasileiro típico se casa admiravelmente com a representação de cordialidade (ligada à não violência) que é, ainda nos dias de hoje, manipulada pelas classes dominantes." (Cerqueira Filho \& Neder, 1978, p. 224)
}

Artigo recebido em: 30/03/2009

Aprovado para publicação em: 15/05/2009 